\section{Who are more insulin resistant, people with IFG or people with IGT?}

Recently, several studies have addressed whether the two risk categories for Type 2 diabetes, impaired fasting glucose (IFG) and impaired glucose tolerance (IGT), represent different populations with regard to insulin resistance, insulin secretion and risk of developing cardiovascular disease. However, the issue remains to be clarified.

Some studies have reported that people with isolated IFG are more insulin resistant than those with normal glucose tolerance (NGT) and that people with isolated IGT exhibit a more severe deficit in insulin secretion than those with IFG $[1,2]$. In contrast, another study showed that insulin resistance is absent in people with IFG, and markedly higher in people with isolated IGT and with both IFG and IGT, whereas defective insulin release is significant only in people with isolated IFG [3]. These studies estimated insulin resistance using the homeostasis model assessment (HOMA) index. Based upon our preliminary experience, the correlation between the HOMA index and the glucose infusion rate value (an index of insulin sensitivity) during the clamp study is lower in people with NGT $(r=-0.573, p<0.01$, $n=21)$ and IGT $(r=-0.533, p<0.0001, n=69)$. Weyer et al. investigated this in Pima Indians using the euglycaemic hyperinsulinaemic clamp method [4]. They reported that all three groups with impaired glucose homeostasis were more insulin resistant than the NGT group, but that there were no differences in insulin sensitivity between the groups. In light of this, we analysed data from our euglycaemic insulin clamp studies [5] as well as insu-

DOI 10.1007/s00125-004-1339-1

Published online: 13 February 2004

(C) Springer-Verlag 2004 lin response during a 75-g oral glucose tolerance test. Mean age and BMI $( \pm \mathrm{SD})$ for our groups were as follows: NGT group $\left(n=45,39.9 \pm 13.5\right.$ years; $\left.23.4 \pm 3.6 \mathrm{~kg} / \mathrm{m}^{2}\right)$, IFG group $(n=10$, $51.5 \pm 11.2$ years; $\left.22.7 \pm 1.9 \mathrm{~kg} / \mathrm{m}^{2}\right)$, IGT group $(n=36,49.8 \pm 12.5$ years; $\left.23.5 \pm 4.2 \mathrm{~kg} / \mathrm{m}^{2}\right)$, IFG and IGT group $(n=11,51.1 \pm 14.2$ years; $25.2 \pm 4.1 \mathrm{~kg} / \mathrm{m}^{2}$ ). As indicated, the people with NGT were generally younger than those in the other groups, but BMI was quite similar in each of the four groups. As shown in Table 1, glucose infusion rate was significantly lower in people with isolated IGT and people with both IFG and IGT than in people with NGT and with IFG. Fasting serum insulin concentrations were higher in the IGT group $(9.8 \pm 5.8 \mu \mathrm{U} / \mathrm{ml})$ than in the NGT group $(7.5 \pm 3.3 \mu \mathrm{U} / \mathrm{ml} ; p<0.05)$, and insulin response tended to be higher in the IGT group and in people with both IFG and IGT than in the NGT and IFG groups throughout the test. This is shown by the area under the curve for insulin $(p<0.05$ for the IFG and IGT group vs the IFG group). Early-phase insulin secretion ( $\Delta$ immunoreactive insulin $/ \Delta$ plasma glucose at $30 \mathrm{~min}$ ) after oral glucose load in the IFG group was lower, but not significantly, than in other groups. The greater insulin response in people with IGT than in those with IFG was also shown by the HOMA beta cell function: $[0.2 \times$ fasting insulin $(\mu \mathrm{U} / \mathrm{ml})] /[$ fasting glucose (mmol/l)-3.5] [6]. Therefore, our result that people with IFG had a more pronounced defect in early insulin response than those with IGT was consistent with previous findings [3, 4, 7] which suggested that acute insulin response is more closely related to the fasting glucose than to the 2-h glucose concentration.

People with IGT as well as those with both IFG and IGT had higher fasting plasma triglycerides and non-esterified fatty acids, and lower HDL cholesterol concentrations than people with NGT and with IFG (see Table 2). Blood lipid profiles illustrate that even non-obese people with IGT show several features of metabolic syndrome. The fact that IFG had no additive effect on the degree of insulin resistance may also imply that having IFG does not, in itself, make someone insulin resistant.

Table 1. Insulin secretion and insulin sensitivity in people with NGT, with IFG, with IGT, and with both IFG and IGT

\begin{tabular}{llllllll}
\hline Group & $n$ (male) & $\begin{array}{c}\Delta \mathrm{IRI} / \Delta \mathrm{PG} \\
\text { at } 30 \mathrm{~min}\end{array}$ & $\begin{array}{c}\text { AUC gluc } \\
(\mathrm{mmol} / \mathrm{lxh})\end{array}$ & $\begin{array}{c}\text { AUC ins } \\
(\mu \mathrm{U} / \mathrm{ml} \times \mathrm{h})\end{array}$ & HOMA-R & HOMA- $\beta$ & $\begin{array}{l}\text { GIR } \\
\left(\mu \mathrm{mol} \cdot \mathrm{kg}^{-1} \cdot \mathrm{min}^{-1}\right)\end{array}$ \\
\hline NGT & $45(30)$ & $0.92 \pm 1.48$ & $14.8 \pm 2.7$ & $82.5 \pm 49.3$ & $1.8 \pm 0.8$ & $0.9 \pm 0.5$ & $34.4 \pm 12.2$ \\
IFG & $10(6)$ & $0.38 \pm 0.10$ & $18.8 \pm 1.7^{\mathrm{a}}$ & $54.8 \pm 21.4^{\mathrm{c}}$ & $1.9 \pm 0.7$ & $0.5 \pm 0.2^{\mathrm{ab}}$ & $41.7 \pm 10.6^{\mathrm{bc}}$ \\
IGT & $36(26)$ & $0.67 \pm 0.81$ & $18.3 \pm 2.1^{\mathrm{a}}$ & $139.3 \pm 184.2$ & $2.4 \pm 1^{\mathrm{a}}$ & $1.1 \pm 0.9$ & $27.2 \pm 12.2^{\mathrm{a}}$ \\
IFG and IGT & $11(9)$ & $0.51 \pm 0.40$ & $22.0 \pm 1.4^{\mathrm{a}}$ & $114.2 \pm 76.8$ & $2.4 \pm 1.1^{\mathrm{a}}$ & $0.6 \pm 0.3$ & $26.7 \pm 11.7$
\end{tabular}

Data are means \pm SD

Abbreviations: IRI, immunoreactive insulin $\cdot \mathrm{PG}$, plasma glucose $\cdot$ AUC gluc and AUC ins, area under the curve for glucose and insulin between 0 and 120 min, respectively, as measured by the sum of the area of three divided rectangles . GIR, glucose infusion rate $\cdot h$, hour $\cdot$ HOMA- $\beta$, homeostasis model assessment beta cell function - HOMA-R, homeostasis model assessment insulin resistance index $\cdot$ IFG, impaired fasting glucose · IGT, impaired glucose tolerance · NGT, normal glucose tolerance ${ }^{\mathrm{a}} p<0.05$ when compared with the NGT group, ${ }^{\mathrm{b}} p<0.05$ when compared with the IGT group, ${ }^{c} p<0.05$ when compared with the IFG and IGT group using the Student's $t$ test 
Table 2. Plasma lipid profile in people with NGT, with IFG, with IGT, and with both IFG and IGT

\begin{tabular}{lllll}
\hline Group & NEFA $(\mathrm{mmol} / \mathrm{l})$ & TG $(\mathrm{mmol} / \mathrm{l})$ & HDLC $(\mathrm{mmol} / \mathrm{l})$ & TC $(\mathrm{mmol} / \mathrm{l})$ \\
\hline NGT & $0.46 \pm 0.24$ & $1.4 \pm 1.5$ & $1.4 \pm 0.4$ & $5.1 \pm 1.0$ \\
IFG & $0.30 \pm 0.56^{\mathrm{a}}$ & $1.1 \pm 0.6^{\mathrm{a}}$ & $1.5 \pm 0.2^{\mathrm{a}}$ & $5.4 \pm 0.6$ \\
IGT & $0.68 \pm 0.56$ & $1.9 \pm 2.3$ & $1.4 \pm 0.4$ & $5.1 \pm 0.9$ \\
IFG and IGT & $0.54 \pm 0.21$ & $2.0 \pm 1.1$ & $1.3 \pm 0.3$ & $5.2 \pm 0.8$ \\
\hline
\end{tabular}

Data are means $\pm \mathrm{SD}$

Abbreviations: NEFA, non-esterified fatty acids ·

TG, triglycerides · HDLC, high density lipoprotein cholesterol · TC, total cholesterol · NGT, normal glucose

The major shortcoming of our study is the limited number of people with isolated IFG, due to the lower incidence of this clinical manifestation. Insulin resistance in people with IGT, as demonstrated in our study, is consistent with the epidemiological evidence that IGT, but not IFG, is associated with an increase in cardiovascular-related mortality [8]. In conclusion, people with IGT are more insulin resistant than those with IFG, and show a compensatory increase in insulin secretion as well as manifestations of metabolic syndrome.

T. Wasada · H. Kuroki - K. Katsumori · H. Arii ·

A. Sato $\cdot$ K. Aoki

Diabetes Center

(formerly the Insulin Resistance Research Group),

Tokyo Women's Medical University,

Shinjuku-ku, Tokyo 162-8666, Japan

T. Wasada $\cdot$ S. Jimba $\cdot$ G. Hanai

Saitama-ken Saiseikai Kurihashi Hospital,

Saitama-ken, Japan

\section{References}

1. Tripathy D, Carlsson M, Almgren P et al. (2000) Insulin secretion and insulin sensitivity in relation to glucose tolerance: lessons from the Botnia Study. Diabetes 49:975-980

2. Hanefeld M, Koehler C, Fuecker K, Henkel E, Schaper F, Temelkova-Kurktschiev T (2003) Insulin secretion and insulin sensitivity pattern is different in isolated impaired glucose tolerance and impaired fasting glucose: the risk factor tolerance $\cdot$ IFG, impaired fasting glucose $\cdot$ IGT, impaired glucose tolerance

a $p<0.05$ when compared with the IFG and IGT group using the Student's $t$ test

in Impaired Glucose Tolerance for Atherosclerosis and Diabetes study. Diabetes Care 26:868-874

3. Carnevale Schianca GP, Rossi A, Sainaghi PP, Maduli E, Bartoli E (2003) The significance of impaired fasting glucose versus impaired glucose tolerance: Importance of insulin secretion and resistance. Diabetes Care 26:1333-1337

4. Weyer C, Bogardus C, Pratley RE (1999) Metabolic characteristics of individuals with impaired fasting glucose and/or impaired glucose tolerance. Diabetes 48:2197-2203

5. Wasada T, Kuroki H, Naruse M et al. (1995) Insulin resistance is associated with high plasma ouabain-like immunoreactivity concentration in NIDDM. Diabetologia 38:792-797

6. Matthews DR, Hosker JP, Rudenski AS, Naylor BA, Treacher DF, Turner RC (1985) Homeostasis model assessment: insulin resistance and beta-cell function from fasting plasma glucose and insulin concentrations in man. Diabetologia 28:412-419

7. O'Rahilly SO, Hattersley A, Vaag A, Gray H (1994) Insulin resistance as the major cause of impaired glucose tolerance: a self-fulfilling prophecy? Lancet 344:585-589

8. Tominaga M, Eguchi H, Manaka H, Igarashi K, Kato T, Sekikawa A (1999) Impaired glucose tolerance is a risk factor for cardiovascular disease, but not impaired fasting glucose: The Funagata Diabetes Study. Diabetes Care 22:920-924

\section{T. Wasada ( )}

Diabetes Center

(formerly the Insulin Resistance Research Group),

Tokyo Women's Medical University, 8-1 Kawada-cho,

Shinjuku-ku, Tokyo 162-8666, Japan

E-mail: tounyo@saikuri.org 